\title{
Re-construindo a História do município de Concórdia através de desafios e imagens: uma perspectiva pedagógica
}

\author{
Leticia L. Leite ${ }^{1}$, Karen A. S. Auler ${ }^{2}$, Myrian I. S. B. Laste ${ }^{3}$ \\ ${ }^{1}$ Faculdade de Informática - Pontifícia Universidade Católica do Rio Grande do Sul \\ (PUCRS) - 90619-900 - Porto Alegre - RS - Brasil. \\ ${ }^{2}$ Núcleo de Tecnologias Educacionais (NTE) - Secretaria de Estado da Educação SC/ \\ Gerência de Educação - 89700-000 - Concórdia - SC - Brasil \\ ${ }^{3}$ Núcleo de Tecnologias Educacionais (NTE) - Secretaria de Estado da Educação SC/ \\ Gerência de Educação - 89700-000 - Concórdia - SC - Brasil
}

leticia.leite@pucrs.br,karen_auler@yahoo.com.br,myrianisabel2000@yahoo.com.br

\begin{abstract}
This article reports the experience of rediscovering a city by solving puzzles and using a mapping records images from the perspective of participants. A new look at the everyday is proposed from challenges, resulting in the unveiling of new images. A renewed pedagogical practice is formed through the proposal, joining the Information Technology and Communications practice at a dynamic and motivating, in which images are revealing this new look.

Resumo. Este artigo relata a experiência de redescobrir uma cidade através da solução de enigmas e de um mapeamento através de registros de imagens sob a perspectiva dos participantes. Um olhar novo sobre o cotidiano é proposto a partir de desafios, ocorrendo o desvendamento de novas imagens. Uma prática pedagógica renovada se configura através da proposta, aliando as Tecnologias de Informação e Comunicação a uma prática dinâmica e motivadora, em que as imagens são reveladoras deste novo olhar.
\end{abstract}

\section{Introdução}

O uso de Tecnologias de Informação e Comunicação (TICs) tem se disseminado pelas diversas áreas do conhecimento e, particularmente na Educação, sua aplicação tem apresentado importantes contribuições. Guimarães e Melo (2008) afirmam que "as tecnologias de produção e circulação de visualidades, devem ser não só levadas em consideração em qualquer análise que envolve as questões educativas, como percebidas como fator de influência sobre as mesmas". Neste sentido, acredita-se que o uso de recursos de imagem e vídeo implicam em especial motivação para os alunos.

A era dos nativos digitais, definida por Prensky (2001), e que caracteriza a geração contemporânea que está habituada ao uso de tecnologias digitais e fluentes na linguagem digital dos computadores, dos jogos eletrônicos e da Internet representa uma das formas de caracterizar os usuários destes recursos e que representam grande parte de nossos alunos atuais. Torna-se, então, importante identificar formas e recursos que 
possam contribuir para o processo de ensino e de aprendizagem e que estejam alinhados às expectativas e anseios deste perfil de usuários.

Segundo Guimarães e Melo (2008), “o envolvimento de questões pertinentes à docência vem buscar na cultura visual o suporte para compreendermos e abrigarmos as novas formas de compreensão da realidade que se configura, bem como abrirmos discussões sobre as representações que se contraponham às hegemônicas, na busca da compreensão do sentido da atividade docente, lembrando que compreender é diferente de entender: é modificar-se, é ir além de si mesmo". Tendo em vista esta perspectiva, apresentamos uma experiência de uso de imagens como auxílio ao processo de ensino e de aprendizagem, que é relatada neste artigo, cujo objetivo é registrar e comentar as experiências vivenciadas a partir da solicitação de um grupo de adolescentes, de aproximadamente 14 anos de idade: unir atividades pedagógicas com desafios e uso de imagens. Os garotos, na época da realização da atividade, cursavam a $8^{\mathrm{a}}$ série do Ensino Fundamental.

Os alunos que participaram desta experiência propuseram unir desafios a serem desvendados através de imagens e de outros recursos, inspirados na leitura de uma coleção de literatura juvenil, entitulada "The 39 Clues" (Haddix (2011), Korman (2011) e Riordan (2009)). A partir desta demanda e sob uma perspectiva pedagógica, a tarefa foi elaborada utilizando como tema central a história do município de Concórdia/SC.

O município de Concórdia localiza-se no Oeste catarinense, na Microrregião do Alto Uruguai, a $493 \mathrm{Km}$ da capital do Estado, Florianópolis. Segundo dados do IBGE (2011), Concórdia conta uma população de 67.249 habitantes (zona urbana: 52.387 e zona rural: 14.862), e uma economia baseada nas atividades agrícolas, industriais e comerciais, com ênfase na suinocultura e na pecuária. A Cidade de Concórdia também se destaca na produção de milho.

\section{Material e Métodos}

O desenvolvimento das tarefas que compõem a atividade foi inspirado em uma coleção de livros entitulada "The 39 Clues", no Brasil, "As 39 Pistas". Nesta coleção de literatura jovem, cada livro tem um autor diferente, sendo que diversos autores da atualidade, como Rick Riordan, Gordon Korman e Peter Lerangis se revezam, dando continuidade à história anterior. Os livros se desenrolam a partir de pistas que vão conduzindo o enredo da história central.

No enredo, dois órfãos descobrem fazer parte de uma família de personalidades que influenciaram os acontecimentos históricos, e precisam decidir se preferem herdar um milhão de dólares ou receber a primeira pista para encontrar o maior tesouro do mundo. Na história, viverão as mais fantásticas aventuras com o objetivo de encontrar este tesouro. Através das pistas, são apresentados acontecimentos da história mundial, transformando-se em uma aula de história em forma de desafio e literatura.

A importância de valorizar e dar seguimento a um trabalho nascido com raízes na literatura fantástica, que estimula a imaginação, se justifica nas palavras de Abramovich (1998): "É através duma história que se podem descobrir outros lugares, outros tempos, outros jeitos de agir e de ser, outra ética, outra ótica... É ficar sabendo História, Geografia, Filosofia, Política, Sociologia, sem precisar saber o nome disso 
tudo e muito menos achar que tem cara de aula...". No "era uma vez" tudo é possível, não é preciso uma explicação racional. Cada leitor entende/interpreta/imagina de acordo com as suas vivências, a sua bagagem, interagindo com o texto e construindo suas próprias significações. Cada um faz sua leitura individual da história: não existe "a leitura", mas a leitura de cada um. A leitura tem sua virtualidade, permitindo abstrair das relações de tempo, do espaço e os acontecimentos. Permite um vir-a-ser, um viajar através do imaginário.

Procurando unir um pouco desta ficção, a fim de estimular o imaginário ao mesmo tempo em que se busca explicação para o real, que se faz presente sob outro olhar, é que os desafios foram pensados. Uma viagem ao conhecido/desconhecido foi proposta, visando a descoberta de aspectos até então despercebidos, em uma exploração física, visual e de aprendizagem, pois como afirma Proust (apud MORIN, 2004) "Uma verdadeira viagem de descoberta não se resume às pesquisas de novas terras, mas envolve a construção de um novo olhar".

As tarefas apresentadas ao grupo de adolescentes se desenvolveram no formato de pistas que deveriam ser descobertas e que identificavam uma tarefa a ser realizada. Cada pista leva à outra, até o desfecho da tarefa. As pistas foram distribuídas em diversos locais da Cidade, tais como a praça central, o museu e a escola, com o objetivo de propiciar aos alunos uma "re-visita" e um novo olhar sobre os locais que fazem parte de seu cotidiano. Após a entrega da tarefa nestes locais, a mesma era postada também no blog criado para a atividade (http://pistasconcordia.blogspot.com/), visando manter o registro de toda a tarefa e a construção de um espaço comum, onde os saberes e experiências pudessem ser compartilhados. É importante salientar que, na definição das atividades, foi dada atenção especial ao perfil do grupo de alunos, que é formado por adolescentes, acostumados ao uso de recursos de tecnologias para comunicação e realização de atividades, que gostam de jogos e, sobretudo, de serem desafiados. Além disso, não foi esquecido o foco na aprendizagem, ou seja, deveria ser proposta muito mais do que uma atividade divertida, mas uma atividade que estimulasse a aprendizagem (Figura 1).

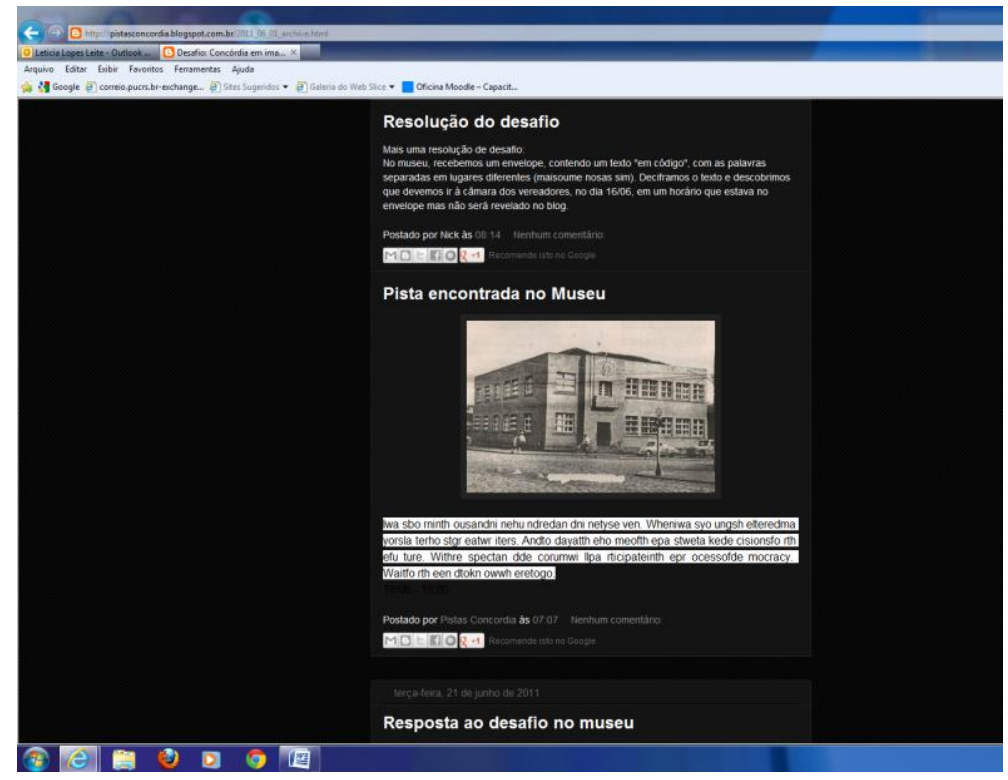

Figura 1. Blog criado para a atividade 
A perspectiva pedagógica foi contemplada através do tema central escolhido, a história do município de Concórdia/SC em forma de desafio, além de trabalhar a leitura e a criação de imagens. A missão do trabalho foi justamente possibilitar aos aprendizes conhecer melhor o município em que moram, seu passado e seu presente, e, através desta motivação, trabalhar leitura e criação de imagens. As imagens do passado e do presente foram elementos constantes no processo, sempre gerando novas imagens, novos olhares e leituras. De acordo com Guimarães e Melo (2008), "A relação entre a cultura visual e educação possibilita a diluição dos diversos campos do conhecimento, propiciando o aprofundamento das discussões sobre cultura, discurso, identidade, diferenças, processos de subjetivação e representação, possibilitando pensar e entender a própria educação, de modo mais complexo e plurifacetado". Especificamente em relação a estes recursos visuais, foram utilizadas nas pistas imagens do passado do município, para que os adolescentes identificassem os locais propostos para os desafios e que foram registrados também no presente pelos alunos ao solucionarem os desafios.

As tarefas envolveram a utilização de várias ferramentas digitais e virtuais, como Google Maps, Google Earth, Wikimapia, álbum de fotografias virtual (tripadvisor), apresentações multimídia como os sites Slideshare e o Prezi, páginas de pesquisa na internet, editores de vídeo e imagens, além de recursos como, por exemplo, dados cartográficos para elaboração do traçado de trajeto e mapeamento do percurso da solução dos desafios. Além disto, as tarefas, ou pistas, foram propostas em diferentes linguagens, em forma de enigmas, tais como códigos numéricos ou alfabéticos, e utilizando outras línguas, como inglês, Braile e Libras (Língua Brasileira de Sinais). Esta atividade tentou diversificar os recursos utilizados nas tarefas, objetivando estimular a participação dos alunos. Neste sentido Guimarães e Melo (2008) afirmam que "se antes nós aprendíamos com um simples 'Bê-a-Bá' de uma cartilha, hoje nossos alunos, muito precocemente, familiarizam-se com uma gama enorme de ferramentas e programas de computador, além de sites com diversas finalidades e ambientes virtuais diversos".

A conclusão deste processo ocorreu pela elaboração das imagens capturadas de forma que representem o hibridismo das novas imagens, onde imagens do passado se fundem com imagens do mesmo local no momento atual. Sendo assim, após a solução de todos os enigmas, foi proposta uma tarefa de elaboração de imagens representativa do percurso realizado para a solução dos desafios. Este processo foi retratado através da criação de uma apresentação multimídia utilizando o software Prezi e que representa a trajetória de descobertas do grupo (http://prezi.com/ca7w2bmgqofk/concordia-emimagens/).

\section{Resultados e Discussão a respeito do trabalho}

Os resultados e discussão sobre o processo que envolveu os alunos na conclusão das tarefas propostas será apresentado enfocando os espaços (re)descobertos através da imagem (seção 3.1) e na teia que envolve o mundo real e o virtual (seção 3.2).

\subsection{Redescobrindo espaços... Desvelando imagens...}

A organização da cidade foi apresentada como uma tentativa de mostrar sua estruturação ao longo dos anos, enfatizando-se o uso de imagens que mostram lugares antigos e imagens que mostram a contemporaneidade. Os adolescentes retrataram a 
formulação da idéia que surge a partir dos desafios e pistas propostos e que reportam ao conhecimento destes locais e suas histórias. As imagens que refletem esta história e o novo olhar sobre os espaços que fazem parte de seu dia-a-dia podem ser visualizadas nas postagens apresentadas no blog construído para a atividade. Surgem, neste contexto, suas subjetividades e suas interpretações de cada espaço explorado. Para Flusser (1985), as imagens que nos rodeiam e sua aparente objetividade são ilusórias, pois na realidade são tão simbólicas quanto o são todas as imagens. Devem ser decifradas por quem deseja captar-lhes o significado. E são símbolos abstratos, que para este autor podem codificar textos em imagens, são metacódigos de textos. A imaginação, a qual devem sua origem, é a capacidade de codificar textos em imagens. Decifrá-las é reconstruir textos, que as imagens significam.

Destaca-se o conhecimento criado e compartilhado pela comunicação através das mídias, como celular, internet, e-mail, blog, fazendo com que a atividade ocorresse em espaços reais e virtuais. Além disso, a motivação na realização da atividade, proporcionada, em grande parte, pelo uso de diferentes recursos, corrobora com o estímulo que as instituições de ensino têm feito para sua incorporação no processo de ensino e aprendizagem. Segundo Santos (1985, p. 6), as atuais relações humanas interagindo no espaço, dão fortes nexos para a compreensão das relações sociais, isso porque antes de serem objetos inertes, são os próprios sujeitos vivificadores dos processos. As relações e interações humanas vêm se transformando com o advento das novas mídias digitais, que permitem estar em vários lugares ao mesmo tempo, sendo que, frequentemente, a virtualidade e a realidade se fundem. Na cibercultura, no mundo mediado pelo computador e pela rede, o eu é múltiplo, fluido e constituído em interações com as máquinas, que é feito e transformado pelas linguagens. Para Turkle (1997), a rede é a virtualidade da realidade, e ao mesmo tempo ela não é, e sim é apenas uma engrenagem em máquinas maiores da língua e mídias de controle.

Com relação às vivências e experiências da atividade aqui relatada, esta questão evidenciou-se, uma vez que as respostas aos desafios, antes de qualquer outra deste recurso, parece impossível que nem todas as respostas se encontrem ali. A interação que parece tão fácil virtualmente torna-se mais "custosa" na "vida real". Jovens habituados a resolver facilmente as mais diversas tarefas colaborativamente e on-line, mostram-se resistentes a buscar a informação na fonte "real". É difícil, inclusive, especificar o que é o real, uma vez que o virtual é a sua realidade. O virtual, muitas vezes, apresenta-se mais real do que o mundo concreto que nos cerca. Fundem-se realidade e virtualidade, e tornam-se espaços de produção de conhecimento, à medida que se interpenetram. Essas realidades são, segundo Levy (1999), os próprios intelectos coletivos e criam suas identidades na interação com novos saberes, sujeitos aprendem e renovam-se. É neste sentido de interação que este autor afirma que não há nenhuma razão pura nem sujeito transcendental invariável. Desde seu nascimento, o pequeno humano pensante se constitui através de línguas, de máquinas, de sistemas de representação que irão estruturar sua experiência.

Em consonância com Pierre Levy, André Parente (1993) ao realizar extensa reflexão sobre a natureza da realidade virtual, diz que o produto das novas máquinas de visão situam-se além da representação e da simulação: a realidade virtual leva-nos diretamente para o domínio da alucinação verídica. Neste sentido, o imaginado e criado virtualmente ganha status de realidade. Isto é verificado através de imagens híbridas, em 
que a realidade retratada foi transformada com o auxílio de ferramentas da virtualidade. A ação de representar o real de forma irreal, em que um museu transforma-se em desenho a carvão no clicar do mouse, por exemplo, torna-se um processo natural, uma brincadeira com a realidade conhecida e a imaginada.

Pierre Levy (1999) situa o espaço do saber, que para este autor, consolida-se no final do século XX com as redes digitais e os universos virtuais. Neste espaço, Pierre Levy diz que a identidade do indivíduo é constituída por imagens dinâmicas, sendo estas geradas pela navegação, transformação e exploração das realidades virtuais.

Com esta nova relação entre real e virtual, surge também uma nova relação com os espaços e com a territorialidade. Território representa o mundo das significações, das ausências e presenças, o que está presente, não somente no momento, mas o que traz dentro de si coisas ausentes ao ato empírico, mas presente nas significações. O que atualmente relaciona-se com o virtual, conforme aborda Parente (1993). A realidade virtual é uma verdadeira janela que se abre para outros mundos: com a ajuda do computador, entramos em mundos simulados que podemos tocar e sentir diretamente, como se fossem verdadeiros. A própria territorialidade virtualiza-se.

De acordo com Deleuze e Guattari (1992, p. 30), o sujeito e o objeto oferecem uma aproximação do pensamento. Pensar não é um fio estendido entre um sujeito e um objeto, nem uma revolução de um em torno do outro. Pensar se faz antes na relação entre o território e a Terra. Neste imaginário consciente é que acontece a ação de redescobrir a cidade a partir do espaço geográfico, onde prédios e monumentos atuam também como meios de comunicação para transmissão e recriação das informações que passam a ser territorializantes, que agem como veículo, que permitem o trânsito entre o passado e o presente.

Para Bougnoux (1994, p. 30), onde julgávamos tratar de coisas, é preciso levar em consideração fluxos, substituir as causas pontuais por sistemas e interações. As atuais relações humanas interagem com o passado para constituir-se o presente e construir o futuro.

O espaço modifica-se, encontra-se nas mídias e nas máquinas uma lógica de renovação para a produção social, onde a vida da comunidade transforma-se e a transforma. $\mathrm{O}$ espaço geográfico com relação à imagem e com as diferentes linguagens e toda pluralidade que envolve o contexto social dá forma e conteúdo às expressões da cidade, ressignificando-a nas interações com a vida humana e o virtual que também a envolve.

\subsection{Relação Cidade Território - Não Território}

A Terra foi o primeiro espaço antropológico da humanidade. Segundo Lévy (1999, p. 141), na Terra o homem paleolítico desenvolveu-se e com ele emergiu a linguagem, a técnica a partir das invenções, da pedra e o laço social, os clãs, tribos e povos. De acordo com Lévy (1999, p. 115), estas três características monitoram a Terra como espaço antropológico. A Terra não é o solo originário, nem o tempo das origens, mas o espaço-tempo imemorial, ao qual não se pode atribuir origem, o espaço "desde sempre presente" da espécie, que contém e supera o começo, o desdobramento e o futuro do mundo humano. 
A Terra não é um planeta, nem mesmo a biosfera, mas um cosmo em que os seres humanos estão em constante comunicação. Para Lévy (1999, p. 149), a espécie humana elabora e re-elabora o planeta pela linguagem, técnicas e organização. Neste sentido, o grupo de alunos re-visitou e re-elaborou seu mundo e seu espaço, a partir de um novo olhar proposto pelo desafio. $\mathrm{O}$ uso de diferentes linguagens, como hieróglifos, braile e LIBRAS, permitiu-os experienciar outras formas de comunicação, assim como possibilitou um novo olhar sobre o outro. Entender a dificuldade de se expressar, imposta pelo uso de linguagens de sinais, ou mesmo pelo uso de símbolos antigos, como os hieróglifos, resultou em um re-pensar sobre a evolução das formas de comunicação e sobre questões tão discutidas na atualidade, como a acessibilidade.

De acordo com Lévy (1999, p.149), o homem na Terra, traça sua trilha, suas passagens, seu habitat, cria seu espaço, sua cidade. A Terra é a memória dos homens. Sua paisagem é o mapa das epopéias, o depósito das sabedorias. Todo espaço vive. Os cantos e relatos contam a Terra. A Terra se lembra dos tempos do sonho, do tempo das origens, que estão sempre presente.

Na Terra, o sujeito do saber é coletivo, é a comunidade, é o grupo, é o clã, o saber que perpassa de geração a geração. Para Lévy, na Terra o saber presente na coletividade é iminente ao ser humano. O saber está presente na própria Terra, nos experimentos, na memória, nos atos, na maneira de viver e ver o mundo. Lévy (1999, p. 177) afirma que, na Terra, quando um ancião morre é uma biblioteca que se queima. A criação do desafio possibilitou que os alunos entendessem que a história da Cidade está retratada não somente nas pessoas, mas nas praças, nos marcos históricos, nas construções, enfim em cada espaço que se cria e em cada pessoa que se forma.

André Parente (1993, p. 68) concorda que nós não cessamos de construir e reconstruir modelos de mundo em nossa mente, usando os dados fornecidos pelos nossos órgãos de sentidos e a capacidade de processamento de informações do nosso cérebro e das nossas linguagens.

De acordo com Lévy (1999, p. 132), no território o corpo é um organismo hierarquizado e a alma aparece como um micropole, um micro polis, um pequeno Estado... Para este autor, a psicologia do território é uma política interiorizada, o ser humano ao identificar-se, após seu nome, identifica seu endereço, seu habitat, o lugar onde vive.

A identidade subjetiva gravita em torno da família, do trabalho e do dinheiro, é a fabricação, circulação e consumo das coisas, informações e imagens que dão identificação ao indivíduo. A partir desta construção de identidade que desterritorializa e até desestrutura os sistemas de sociabilidade e identidade dos espaços anteriores, surgem os signos da identidade no espaço mercantil (Lévy, 1999, p. 133).

$\mathrm{Na}$ atualidade, pensar sobre a identidade gera ainda mais reflexões e questionamentos. Com o advento das novas Tecnologias de Informação e Comunicação, o sujeito passa a ter outra forma de se comunicar, de interagir, de perceber o mundo. As redes eletrônicas permitem uma nova relação com a subjetividade. Através delas, é possível representar a si mesmo, transportando-se no tempo e no espaço. A respeito disto, Angerer (1994) no discurso sobre a nova tecnologia - o corpo e a identidade, afirma que é suposto tornar-se inútil, ou seja, já desapareceram no ambiente eletrônico. 
A partir de tantas inovações, portanto, não só o conceito de identidade, como também o conceito de território passam a ser repensados. Na cultura tecnológica, antigos dualismos e seguras fronteiras são postas em xeque, com o desenvolvimento das tecnologias, a internet popularizou-se. Segundo Tucherman (1999): a internet tornou mais familiar, tornou cotidiana e doméstica a experiência da erosão das fronteiras no que se refere à nossa idéia de identidade, banalizando a virtualização do mundo na cultura da simulação. É possível perceber esta erosão de fronteiras na atuação das novas gerações e na sua relação com o espaço e o tempo.

No trabalho aqui apresentado, também foi percebido quão tênue é a linha divisória entre real e virtual, ao observar os participantes buscarem informações na rede, situarem-se melhor no espaço virtual do que no real, ao virtualizarem as informações obtidas, transitando com naturalidade entre os dois "mundos".

\section{Conclusões}

O trabalho com imagens surge da necessidade de trazer à memória a organização espacial de determinados lugares e contextos históricos estudados. Procurou-se entender o meio, conhecer sua cidade, interagir com ela, com seu espaço, seu acontecer envolvendo todos os elementos que concorrem para sua existência, nesta interação através da arte retratada e eternizada na fotografia, que envolve elementos de seu contexto geográfico e histórico. Concordando, então, com o exposto por Santos (2009, p. 468) ao dizer que: "[...] a arte na sua condição sistêmica aproxima cada um dos seus elementos constituintes, artista, obra, interator, entorno e contexto, em um processo relacional interno concorrendo para a sua autorreferencialidade. A partir de uma dinâmica que engendra o caráter objetivo e subjetivo de uma ação, aquela que realizamos como interadores nesse processo, e com a obra, a sensível emergência da artemidia parece surgir como uma experiência vivenciada a partir do olhar de dentro de um "observador"”.

A experiência da arte vivenciada transforma o envolvido no processo. A imagem é um elemento que tem um grande potencial artístico, além do apelo e impacto inerentes a ela. Uma imagem é muito representativa, e por isso mesmo, esta linguagem deve ser apropriada e trabalhada pela Educação. "Vivemos na era da imagem. Precisamos alfabetizar o aluno também nesse contexto para que saiba analisar criticamente um programa de tv, um filme, uma fotografia, a reportagem de um jornal e até a internet. [...] As novas tecnologias, até mesmo o celular, tão combatido nas escolas, podem transformar-se em ótimos instrumentos a serviço da educação." (Michelon, 2008).

É possível afirmar que a relação com as imagens vem se transformando ao longo dos tempos, sobremaneira na contemporaneidade. Se, há algum tempo, a produção de imagens era privilégio de poucos, atualmente, ela está ao alcance de todos, e por isto mesmo, torna-se banal. É certo que, atualmente, as imagens não mais se revestem do caráter de permanência que até algum tempo as acompanhava. Eram um registro fiel, uma memória. Se tínhamos álbuns de fotografias, com algumas fotografias "reveladas", bem selecionadas, hoje temos seus correspondentes virtuais, com diversas possibilidades de publicação, edição, manipulação. Bauman (2001) utiliza os termos liquidez e fluidez para descrever a cultura contemporânea, o que se aplica perfeitamente às imagens da contemporaneidade. Imagens hoje são fluidas, transformáveis, híbridas, e, muitas vezes, descartáveis. 
É papel de um trabalho pedagógico que explora a leitura e a produção de imagens, promover um pensar crítico, a busca por uma perspectiva de imagens significativas e relevantes, capazes de conferir significados e proporcionar um novo olhar. Com o auxílio das modernas ferramentas midiáticas, o trabalho pautado na imagem como representação da historicidade, pode ocorrer de forma significativamente interessante, atraente e resultar em um novo olhar sobre o cotidiano, sobre o território, sobre os espaços de interação. "Numa perspectiva histórica, as visualidades do cotidiano influenciam significativamente as relações sociais e de aprendizagem, considerando principalmente que a imagem não é somente mais um elemento, mas que tem sido o elemento chave na sociedade atual, cuja concentração e convergência têm como suporte o aparato tecnológico e os meios de comunicação. Essas questões nos fazem reconhecer a riqueza dos trabalhos que envolvem as imagens, visto serem espaços de diversidade, heterogeneidade e hibridismo". (Guimarães e Melo, 2008)

As TICs estiveram presentes em todo o processo de re-descoberta da cidade, seja através do uso de equipamentos como câmeras digitais e celulares para a captura de imagens, seja através do uso de programas para edição de imagens, ou ainda a partir da pesquisa, interação e autoria através da internet. O próprio uso do blog como meio de publicação e interação, já se configura em utilização pedagógica de Tecnologia de Informação e Comunicação.

A partir do momento em que o aprendiz passa a atuar no espaço, registrando-o a seu modo, com um olhar diferenciado, ele deixa sua marca, e é marcado por este processo. Registrar a sua percepção do território no qual está inserido, repensando-o, redesenhando-o virtualmetne, se constitui em uma experiência indelével, em que, mais importante do que demarcar o que é virtual ou real, é sentir-se integrante do processo de construção histórica, que age e faz diferença.

\section{Referências}

Abramovich, F. (1989), "Literatura infantil: gostosuras e bobices", Editora Scipione.

Angerer, M. (2012) "The Body as Interface", http://www.c3.hu/events/97/flusser/participantstext/angerer.html, Julho.

Baumann, Z. (2001), "Modernidade líquida”, Editora Zahar.

Bougnoux, D. (1994), "Introdução às Ciências da Informação e da Comunicação", Tradução Guilherme João Freitas Teixeira, Editora Vozes.

Prefeitura Municipal Concordia. "Homepage Institucional da Prefeitura Municipal de Concórdia/SC" http://www.concordia.sc.gov.br/conteudo/?item=26172\&fa=10992, Maio.

Deleuze, G. e Guattari, F. (1992), "O que é Filosofia?” Tradução de Bento Prado Jr. e Alberto Alonso Muñoz, Editora 34.

Flusser, V. (1985), "Filosofia da caixa preta", Editora Hucitec.

Gertel, S. (1996), "A Filosofia das Técnicas. Em Ensaios da Geografia Contemporânea”, Ana Fani Alessandri Carlos (Org.), Editora Hucitec. 
Guimarães, L. e Melo, R. (2011) "As influências das imagens no processo de aprendizagem a partir das inovações tecnológicas", http://arte.unb.br/7art/textos/raquelMelo.pdf, Janeiro.

Haddix, M. (2011), “O Último Desafio”. Editora Ática. Coleção The 39 Clues.

Korman, G. (2011), “O Código do Imperador”. Editora Ática. Coleção The 39 Clues.

Levy, P. (1993), “Cibercultura”. Tradução de Carlos Irineu da Costa, Editora 34. . (1999), "A inteligência Coletiva: por uma antropologia do ciberespaço". Tradução de Luiz Paulo Rouanet, Loyola, $2^{\mathrm{a}}$ edição.

Michelon, V. (2008) "Educar através da produção de imagens". $<$ http://www.mundojovem.com.br/projetos/pedagogicos/projeto-educar-atraves-daproducao-de-imagens.php $>$, Dezembro.

Morin, E. (2004), "Educação e complexidade: os sete saberes e outros ensaios". Maria da Conceição Almeida, Edgar de Assis Carvalho (Orgs.), Cortez, 2a edição.

Parente, A. (1993), "Introdução. Os Paradoxos da Imagem-Máquina. Em ImagemMáquina A Era das Tecnologias do Virtual. Parente”, André (Org), Tradução: Rogério Luz et all, Editora 34.

Prensky, M. (2001) "Digital natives, digital immigrants". $<$ http://www.marcprensky.com/writing/Prensky\%20-

\%20Digital\%20Natives,\%20Digital\%20Immigrants\%20-\%20Part1.pdf>, Dezembro.

Riordan, R. (2009), “O labirinto dos Ossos”, Editora Ática. Coleção The 39 Clues.

Santos, N. (2004), "Arte (e) Tecnologia em sensível emergência com o entorno digital: Projetos Brasileiros", Tese de Doutorado em Artes Visuais, História, Teoria e Crítica, PPGAV/UFRGS.

Santos, N. (2000) "Emergência da Arte e Tecnologia: Por uma ação incorporada". In: $18^{\circ}$ Encontro da associação nacional de Pesquisadores em artes Plásticas, Transversalidades nas Artes Visuais, p. 2465-2476, Brasil.

Taylor, M. e Saarinen, E. (1994). “Imagologies”, Media Filosofia.

Tucherman, I. (2000) "Entre anjos e cyborgs". In: Revista de Comunicação e Linguagens, p. 157-171, Lisboa.

Turkle, S. (1997), "Life on the Screen. Identity in the Age of the Internet", Simon \& Schuster. 